Studi Francesi

STUDI

Rivista quadrimestrale fondata da Franco Simone

163 (LV | I) | 2011

Varia

\title{
Chevalier de Mouhy, La Mouche ou les Aventures de M. Bigand
}

Vittorio Fortunati

\section{(2) OpenEdition}

Journals

\section{Edizione digitale}

URL: http://journals.openedition.org/studifrancesi/5957

DOI: ERREUR PDO dans/localdata/www-bin/Core/Core/Db/Db.class.php L.34 : SQLSTATE[HYO00]

[2006] MySQL server has gone away

ISSN: 2421-5856

\section{Editore}

Rosenberg \& Sellier

\section{Edizione cartacea}

Data di pubblicazione: 1 mai 2011

Paginazione: 172

ISSN: 0039-2944

Notizia bibliografica digitale

Vittorio Fortunati, «Chevalier de Mouhy, La Mouche ou les Aventures de M. Bigand», Studi Francesi [Online], 163 (LV | I) | 2011, online dal 30 novembre 2015, consultato il 07 janvier 2021. URL: http:// journals.openedition.org/studifrancesi/5957 ; DOI: https://doi.org/ERREUR PDO dans /localdata/ www-bin/Core/Core/Db/Db.class.php L.34 : SQLSTATE[HY000] [2006] MySQL server has gone away

Questo documento è stato generato automaticamente il 7 janvier 2021.

\section{(c) (i) (9)}

Studi Francesi è distribuita con Licenza Creative Commons Attribuzione - Non commerciale - Non opere derivate 4.0 Internazionale. 


\title{
Chevalier de Mouhy, La Mouche ou les Aventures de M. Bigand
}

\author{
Vittorio Fortunati
}

\section{NOTIZIA}

CHEVALIER DE MOUHY, La Mouche ou les Aventures de M. Bigand, édition de René DÉMORIS et Florence MAGNOT-OGILVY, Paris, Classiques Garnier, («Bibliothéque du xviiie siècle», 2), 2010 , pp. 662.

1 Charles de Fieux, cavaliere di Mouhy (1701-1784), fu sotto molti aspetti quello che oggi definiremmo un autore 'commerciale'. Nobile ma povero, con una famiglia numerosa da nutrire, pubblicò un gran numero di titoli, spaziando dalla cronaca mondana all'imitazione sfacciata dei romanzieri più in voga, soprattutto Marivaux e Prévost. Il successo di pubblico che ottenne fu pari alla sufficienza (per non dire al disprezzo) con cui lo trattarono i critici e gli storici della letteratura. Una sua più adeguata collocazione nell'ambito della narrativa settecentesca data dalla seconda metà del xx secolo: a tale 'riabilitazione' contribuì anche Henri Coulet, a cui si deve la recente edizione de La Paysanne parvenue (Paris, Desjonquères, 2005).

La Mouche è un romanzo in prima persona non privo di agganci con la vita dell'autore (ci riferiamo, per esempio, al suo soggiorno alla Bastiglia e alla sua attività d'informatore della polizia). Il protagonista, Bigand, caratterizzato fin dall'infanzia (come suggerisce il titolo) da un'invincibile curiosità e dalla capacità di trarne vantaggio, vive una serie di peripezie al limite del verosimile, prima di raggiungere una condizione agiata, a fianco della donna che ama. Nonostante questo (apparente?) lieto fine, colpisce il cinismo con cui nell'opera in oggetto è rappresentata la condizione umana, non tanto per la descrizione di una società dominata dalla violenza e dall'ingiustizia, quanto per una sostanziale giustificazione della diffidenza e della doppiezza, anche nell'ambito dei sentimenti: l'amicizia e l'amore, infatti, sembrano fondati più sull'interesse o sul capriccio, che sulla stima o sulla passione. Bigand, che 
pure è in grado di innamorarsi e vorrebbe essere amato, deve prendere coscienza di questa realtà e adeguarsi ad essa.

3 Mouhy pubblicò per la prima volta La Mouche nel 1736; una Suite uscì nel 1742, mentre nel 1777 l'opera riapparve ristrutturata e corretta. Questa terza versione costituisce la base dell'edizione di cui rendiamo conto, mentre delle altre due sono fornite le varianti. Il testo, modernizzato e corredato da utili note lessicali ed esplicative, è preceduto da una prefazione di René Démoris, centrata sull'influsso di vari generi, dal romanzo picaresco alla novella storica, e da un'introduzione di Florence Magnot-Ogilvy, che ripercorre la vita dello scrittore e la storia delle tre versioni successive del romanzo. 